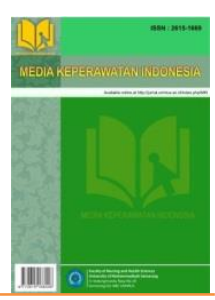

Research article

\title{
Changes of Health Related Quality of Life Dimensions In Hemodialysis Patients
}

\author{
Wantonoro Wantonoro' ${ }^{1}$, Arida Rahmawati ${ }^{2}$ \\ 1 Fakultas Ilmu Kesehatan, Universitas 'Aisyiyah Yogyakarta \\ 2 Rumah Sakit PKU Muhammadiyah Bantul, D.I Yogyakarta
}

\section{Article Info}

Article History:

Accepted Oct 9th, 2020

\section{Keywords:}

Health-related quality of life; Hemodialysis

\section{PENDAHULUAN}

Kerusakan organ ginjal bersifat irreversible, dan berdampak pada kondisi kesehatan serta merupakan penyebab langsung mortalitas dan morbiditas pada pasien gagal ginjal kronik (GGK) (Zipes, 2018). Secara global, telah dilaporkan bahwa 11$13 \%$ orang di seluruh dunia telah mengalami kerusakan ginjal pada stage ketiga (Hill et al., 2016). Prevalensi GGK di Indonesia tercatat sebesar $3,8 \%$ pada tahun 2018, dan menunjukan peningkatan 1,8\% dari tahun 2013 (Riskesdas, 2018). Propinsi Yogyakarta tercatat sebagai 3 besar propinsi dengan prevalensi yang tinggi

Corresponding author:

Wantonoro

oneto_ns@yahoo.com

Media Keperawatan Indonesia, Vol 3 No 3, October 2020

e-ISSN: 2615-1669

ISSN: 2722-2802

DOI: https://doi.org/10.26714/mki.3.3.2020.159-165 dengan penduduk usia diatas 15 tahun menjalani hemodialysis setelah propinsi Jakarta dan Bali (Riskesdas, 2018). Laporan lain menunjukan bahwa prevalensi GGK di propinsi Yogyakarta 0,1\% lebih tinggi dari rerata nasional (Zega, Subronto, \& Padmawati, 2018).

Hemodialysis merupakan salah satu prosedur medis yang bertujuan untuk menggantikan fungsi ginjal yang dilakukan secara terus-menerus sepanjang kehidupan pasien, dengan frekuensi bervariasi untuk setiap individu (Vassalotti et al., 2016; Webster, Nagler, Morton, \& Masson, 2017), dengan rerata dua sampai tiga kali dalam 
seminggu, atau sepuluh sampai dengan lima belas jam perminggu (Rahayu, Ramlis, \& Fernando, 2018). Berbagai penelitian tentang pasien hemodialysis telah melaporkan bahwa terdapat masalah kesehatan yang serius dan sangat berkaitan dengan perubahan kualitas hidup (U. Joshi et al., 2017; Park, Baek, \& Jung, 2016; Ramatillah, Syed Sulaiman, Khan, \& Meng, 2017). Asuhan keperawatan pada pasien yang menjalani hemodialysis akan berlangsung secara terus menerus (longterm care), dan dipengaruhi oleh berbagai faktor yang sangat mempengaruhi kesejahteraan fisik dan psikis pasien berkaitan dengan adanya kerusakan ginjal dan prosedur hemodialysis, hal ini secara umum disebut sebagai kualitas hidup yang berhubungan dengan penyakit tertentu atau Health-Related Quality of Life (HRQoL) (V. D. Joshi, 2014). Kualitas hidup pasien yang menjalani hemodialysis menjadi hal yang menarik perhatian termasuk dalam ilmu keperawatan, karena hakikatnya tujuan ahir dari hemodialysis adalah sebagai alternative menggantikan fungsi ginjal dan pada hasil ahir yang diharapkan adalah mempertahankan kualitas hidup pasien yang berlangsung sepanjang kehidupan pasien. Konsep HRQoL didefinisikan sebagai penilaian subyektif dari dampak penyakit dan pengobatannya di seluruh domain fisik, psikologis, fungsi sosial dan kesejahteraan (Romero, VivasConsuelo, \& Alvis-Guzman, 2013). Skor HRQoL yang rendah merupakan prediktor independent yang kuat untuk pasien menjalani rawat inap serta dapat meningkatkan resiko mortalitas (Feroze et al., 2011; Perl et al., 2017) sehingga menjadi penting untuk diperhatikan.

Pemahaman pada perubahan dimensi $H R Q o L$ secara menyeluruh pada populasi ini menjadi hal yang seharusnya diketahui untuk memberikan dasar merancang sebuah program berdasarkan kebutuhan dimensi bio-psiko-sosial, serta sebagai dasar informasi memprediksi perubahan dimensi HRQoL serta memberikan program perawatan berdasarkan perspective pasien yang menjalani hemodialysis. Beberapa studi di Indonesia memberikan telah gambaran bahwa terdapat perbedaan penurunan pada masing-masing dimensi kualitas hidup pasien hemodialysis (Mulia, Mulyani, Pratomo, \& Chusna, 2018; Suwanti, Taufikurrahman, Imron, \& Wakhid, 2017), namun belum terdapat penelitian secara spesifik mengenai perubahan/trend dimensi kualitas hidup pasien hemodialysis serta predictors yang mempengaruhi trend kualitas hidup pada populasi tersebut. Sehingga diperlukan sebuah tinjauan berdasarkan evidence/penelitian sebagai landasan dalam upaya melakukan asuhan keperawatan pada pasien yang menjalani hemodialisa secara komprehenship berdasarkan trend perubahan HRQoL pasien yang menjalani hemodialisa. Tujuan peneltian ini untuk mengetahui trend dan prediktors dimensi HRQoL pada pasien hemodialysis.

\section{METODE}

Penelitian kuantitatif dengan pendekatan longitudinal design, dengan melakukan pengukuran dimensi $H R Q o L$ pada pasien menjalani hemodialysis secara rutin pada setiap bulannya pada tiga bulan terahir. Instrument: Short form-36 (SF-36) digunakan sebagai instrument evaluasi trend dimensi HRQoL. SF-36 meliputi 8 dimensi: (1) fungsi dari fisik; (2) keterbatasan peran berkaitan dengan kondisi fisik; (3) pengalaman nyeri tubuh; (4) vitalitas atau daya hidup; (5) kesehatan secara umum; (6) kepampuan dalam fungsi sosial; (7) keterbatasan peran berkaitan dengan kondisi emosional; dan (8) kesehatan atau status mental. SF-36 dilaporkan valid (Cronbach's $\alpha$ : 0.78) untuk mengukur HRQoL pada pasien hemodialysis (Abd ElHafeez et al., 2012; Ricardo et al., 2013), termasuk untuk SF-36 versi Indonesia telah dinyatakan valid (Cronbach's $\alpha \quad>0,70$ ) (Novitasari, Perwitasari, \& Khoirunisa, 2016; Salim, Yamin, Alwi, \& Setiati, 2017). 
Prosedure penelitian: penelitian dilakukan setelah mendapatkan surat etik dan ijin penelitian dari tempat penelitian (Nomor surat etik: 1433/KEP-UNISA/II/2020, dan Nomor surat ijin penelitian: 0321/KET/B/02.20). Pengambilan sampel dilakukan dengan accidental sampling pada periode bulan Desember 2019 sampai dengan Juli 2020 di ruang hemodialysis RS PKU Muhammadiyah Bantul. Proses pengumpulan data dilakukan dengan faceto-face interview oleh peneliti dan respondent. Untuk menentukan perbedaan trend dan predictor secara keseluruhan dalam variabel antara subyek, pendekatan analiysis ststistik generalized estimating equations (GEE) telah digunakan dalam penelitian ini.

\section{HASIL}

Terdapat 30 respondent atau sampel yang mengikuti penelitian ini pada pengukuran pertama, sedangkan pada pengukuran ke- 2 ada 28 respondents $(2$ respondents dropout; 1 meninggal dunia, 1 dalam keadaan kritis), dan pada ahirnya yaitu pada pengukuran ke-3 terdapat 27 pasien yang dapat berpartisipasi (dari 28 respondent, 1 respondents dropout; karena meninggal dunia). Rerata usia respondent yaitu 52 tahun $(\mathrm{SD}= \pm 12.8)$, dan sebagian besar merupakan pasien dengan jenik kelamin laki-laki (67 \%) dan lebih dari separuh respondent telah menyelesaikan level pendidikan SMA atau sekolah tinggi tinggi $(57 \%)$, serta sebagain besar yaitu
86.7\% respondent memiliki penyakit penyerta seperti diabetes mellitus, hipertensi dan nyeri sendi. (Tabel 1)

Hasil uji statistic Generalized estimating equations (GEE) didapatkan hasil bahwa secara umum semua dimensi pada HRQoL mengalami perubahan baik pada untuk perubahan pada pengukuran pertama dan pengukuran ke-dua kecuali pada dimensi nyeri $(\beta=-.315 ; \quad 95 \% \mathrm{CI}=\quad-.684-.055$; $p=.095)$, serta perubahan pada pengukuran kedua dan ketiga semua dimensi mengalami perubahan secara signifikan kecuali fungsi peran yang berhubungan dengan emosional pasien $\quad(\beta=-.410 ; \quad 95 \% \mathrm{CI}=-.894-.074$; $p=.097)$, namun menariknya bahwa terdapat satu dimensi yang mengalami perubahan positive secara signifikan yaitu fungsi social pada pengukuran pertama dan kedua $(\beta=1.41 ; 95 \% \mathrm{CI}=-1.087-1.740$; $p=.001)$, serta pada pengukuran ke-dua dan ketiga $(\beta=.169 ; 95 \% \mathrm{CI}=-.239-.576$; $p=.001)$. Perubahan peningkatan juga signifikan pada pengukuran pertama dan ketiga $(\beta=1.582 ; 95 \% \mathrm{CI}=1.141-2.024$; $p=.001)$.

Usia merupakan predictor hampir pada semua dimensi seperti: fungsi fisik; keterbatasan peran, fisik; fungsi sosial; keterbatasan peran emosional ( $p=.001)$. Comorbidities berpengaruh terhadap dimensi nyeri $(p=.05)$. Sementara Pendidikan berpengaruh pada peningkatan dimensi emosi dan mental health $(p=.001)$. (Tabel 2).

Tabel 1

Karakteristik respondents

\begin{tabular}{|c|c|c|c|c|c|c|}
\hline Indikator & $\mathrm{f}$ & $\%$ & $\mathrm{f}$ & $\%$ & $\mathrm{f}$ & $\%$ \\
\hline \multicolumn{7}{|l|}{ Jenis Kelamin } \\
\hline Laki-laki & 23 & 67,7 & 21 & 75 & 20 & 74 \\
\hline Perempuan & 7 & 23,3 & 7 & 25 & 7 & 26 \\
\hline \multicolumn{7}{|l|}{ Pendidikan } \\
\hline Tidak sekolah & 1 & 3 & 1 & 3,6 & 1 & 3,7 \\
\hline Sekolah Dasar & 6 & 20 & 5 & 18 & 5 & 18,5 \\
\hline SMP-SMA & 6 & 20 & 6 & 21 & 6 & 22,2 \\
\hline Pendidikan Tinggi & 17 & 57 & 16 & 57 & 15 & 55,6 \\
\hline \multicolumn{7}{|l|}{ Penyakit Penyerta } \\
\hline Memiliki penyakit penyerta & 26 & 86,7 & 25 & 82 & 24 & 88,9 \\
\hline Tidak memiliki penyakit penyerta & 4 & 13,3 & 3 & 18 & 3 & 11,1 \\
\hline
\end{tabular}

Sumber: data primer (2020) 
Tabel 2

Perubahan dimensi HRQoL by predictors (usia, pendidikan, Co-morbidities)

\begin{tabular}{|c|c|c|}
\hline Indikator & $\mathrm{B}$ & $\mathrm{p}$ \\
\hline \multicolumn{3}{|l|}{ Nyeri } \\
\hline Usia & 0,019 & 0,038 \\
\hline Pendidikan & 0,194 & 0,435 \\
\hline Co-morbidities & 0,936 & 0,050 \\
\hline \multicolumn{3}{|l|}{ Kesehatan secara umum } \\
\hline Usia & $-0,015$ & 0,392 \\
\hline Pendidikan & 10,72 & 0,218 \\
\hline Co-morbidities & $-0,862$ & 0,150 \\
\hline \multicolumn{3}{|l|}{ Vitalitas/energi } \\
\hline Usia & 0,013 & 0,346 \\
\hline Pendidikan & 0,064 & 0,902 \\
\hline Co-morbidities & $-0,176$ & 0,642 \\
\hline \multicolumn{3}{|l|}{ Fungsi sosial } \\
\hline Usia & $-0,016$ & 0,046 \\
\hline Pendidikan & $-0,066$ & 0,776 \\
\hline Co-morbidities & $-0,289$ & 0,256 \\
\hline \multicolumn{3}{|c|}{ Keterbatasan peran berkaitan dengan kondisi emosional } \\
\hline Usia & $-0,024$ & 0,000 \\
\hline Pendidikan & 0,519 & 0,000 \\
\hline Co-morbidities & 0,204 & 0,291 \\
\hline \multicolumn{3}{|l|}{ Kesehatan mental } \\
\hline Usia & 0,030 & 0,003 \\
\hline Pendidikan & 20,778 & 0,000 \\
\hline Co-morbidities & 0,037 & 0,920 \\
\hline \multicolumn{3}{|l|}{ Fungsi fisik } \\
\hline Usia & $-0,131$ & 0,000 \\
\hline Pendidikan & $-0,436$ & 0,575 \\
\hline Co-morbidities & 0,694 & 0,464 \\
\hline \multicolumn{3}{|c|}{ Keterbatasan peran berkaitan dengan kondisi fisik } \\
\hline Usia & $-0,036$ & 0,000 \\
\hline Pendidikan & $-0,369$ & 0,104 \\
\hline Co-morbidities & 0,178 & 0,666 \\
\hline
\end{tabular}

Sumber: data primer (2020)

\section{PEMBAHASAN}

HRQoL merupakan satu komponen utama yang bersifat subyektif untuk kesejahteraan hidup pasien tertentu (Romero et al., 2013). HRQoL pada penelitian ini diukur menggunakan instrument SF-36 yang meliputi 8 dimensi yaitu; fungsi dari fisik; keterbatasan peran berkaitan dengan kondisi fisik; pengalaman nyeri tubuh; vitalitas atau daya hidup; kesehatan secara umum; kepampuan dalam fungsi sosial; keterbatasan peran berkaitan dengan kondisi emosional; dan kesehatan atau status mental (Abd ElHafeez et al., 2012; Ricardo et al., 2013). Secara umum, semua dimensi yang ada tampak menunjukan trend yang negative pada populasi/respondent penelitian ini seperti penurunan fungsi fisik; peningkatan keterbatasan peran berhubungan dengan keadaan fisik; peningkatan nyeri tubuh yang dialami; penurunan vitalitas/daya hidup; penurunan kesehatan secara umum; dan peningkatan keterbatasan peran berhubungan dengan keadaan emosional. Namun menariknya bahwa terdapat dimensi yang mengalami peningkatan pada penelitian ini yaitu dimensi fungsi sosial. Beberapa study telah melaporkan bahwa semakin lama pasien menjalani hemodialisa akan berkorelasi dengan penurunan level kualitas hidup pasien (Anees, Hameed, Mumtaz, Ibrahim, \& Saeed Khan, 2011; Suwanti et al., 2017) hal ini menegaskan bahwa secara umum terjadi penurunan $H R Q o L$ pada pasien yang menjalani hemodialisa pada semua dimensi kualitas hidupnya, hal ini disebabkan oleh progress buruk dari gagal ginjal kronik yang bersifat 
progressive dan irreversible yang juga akan berdampak pada system/organ tubuh yang lain sebagai mekanisme kompensasi tubuh dan komplikasi atau efek selama menjalani terapi dialysis (Dąbrowska-Bender, Dykowska, Żuk, Milewska, \& Staniszewska, 2018). Terdapat berbagai macam komplikasi pada dialysis diantaranya meningkatkan rasa kelelahan, perasaan atau sensai nyeri, gangguan qualitas dan kuantitas tidur, napsu makan yang menurun, mual muntah, terjadinya edema, mengalami peningkatan tekanan darah dan anemia (Dąbrowska-Bender et al., 2018).

Menariknya bahwa ditemukan dimensi yang memiliki kecenderungan bertahan atau meningkat yaitu dimensi fungsi sosial. Kecenderungan peningkatan pada dimensi fungsi social secara umum disebabkan oleh support system seperti peran keluarga dan peer group serta komunikasi dalam asuhan keperawatab yang dilakukan oleh perawat yang dirasakan oleh pasien (Theodoritsi et al., 2016). Dukungan keluarga merupakan faktor penting yang berfungsi sebagai sistem pendukung bagi pasien dalam menghadapi masalah kesehatan (Winata, Putranto, \& Fanani, 2017), termasuk pada pasien hemodialysis (Varghese, 2018). Study menunjukan bahwa dukungan yang dirasakan oleh pasien akan berpotensi meningkatkan strategi keefektifan koping, kemampuan dalam penyesuaian diri terhadap kondisi, serta berdampak baik terhadap kesejahteraan baik fisik maupun psikologis seseorang (Untas et al., 2011), hal ini menegaskan bahwa semakin baik dukungan keluarga maka akan meningkatkan kualitas hidup pasien. Peningkatan fungsi sosial didapatkan ketika pasien dapat berinteraksi dengan keluarga secra rutin di rumah, dan sesama pasien di rumah sakit yang menjalani hemodialisa secara rutin (yang dilakukan dua sampai tiga kali dalam seminggu) serta adanya dukungan dari perawat yang mendampingi dalam setiap sesi hemodialisa. Hal ini didukung oleh studi lain yang melaporkan bahwa karakteristik klinis dan persepsi pasien berhubungan dengan dukungan sosial yang dirasakan, pemberian perawatan individual yang dilakukan secara holistik untuk pasien hemodialisis serta adanya dukungan sosial dalam praktik klinis sehari-hari dirumah sakit (Alexopoulou et al., 2016; Theodoritsi et al., 2016).

Usia dan co-morbidities merupakan predictor yang penting dalam perubahan semua dimensi $H R Q o L$, semakin tinggi usia (semakin tua) maka akan berdampak pada semakin menurunnya semua dimensi HRQoL. Studi melaporkan bahwa kualitas hidup pada setiap periode usia akan berbeda dan dipengaruhi oleh banyak faktor, diantaranya co-morbidities seseorang (Cha \& Han, 2020; Elhadad, Ragab, \& Atia, 2020). Faktor lain yang berpengaruh pada dimensi $H R Q o L$ terutama pada emosi dan mental health dimensi adalah status pendidikan termasuk informasi yang didapatkan, semakin tinggi pendidikan dan semakin terpapar seseorang dengan informasi maka secara psikologis akan semakin baik dalam perubahan untuk mampu memanajemen status emosi dan kondisi kesehatan mental. Study sebelumnya telah melaporkan bahwa terdapat korelasi yang kuat dan positif antara level pendidikan dan kesehatan mental pada usia dewasa, tingkat pendidikan yang lebih tinggi dianggap meningkatkan keterampilan seseorang, memberikan keuntungan struktural yang penting dalam kontek berpikir dan memutuskan sesuatu, dan meningkatkan dalam memberdayakan mekanisme penanganan yang lebih baik, yang semuanya mengarah pada kesehatan mental yang lebih baik (Halpern-Manners, Schnabel, Hernandez, Silberg, \& Eaves, 2016).

\section{SIMPULAN}

Walaupun terdapat beberapa limitasi dalam penelitian diantaranya yaitu heteregonity terhadap durasi/lama pasien menjalani hemodialysis dan sample size yang minimal disertai dengan adanya dropout, namun 
secara umum penelitian ini menberikan informasi bahwa dimensi HRQoL pada pasien hemodialisys menurun seiring dengan waktu atau lama pasien menjalani hemodialisa, tetapi fungsi sosial masih memiliki potensi untuk dipertahankan atau ditingkatkan. Variabel usia, co-morbidities dan pendidikan terkonfirmasi merupakan faktor yang memprediksi perubahan dimensi $H R Q O L$ pada populasi ini, sehingga harus menjadi perhatian khusus pada asuhan keperawatan.

Implikasi keperawatan dari penelitian ini yaitu untuk meningkatkan dan melibatkan support system berupa peran sosial baik keluarga, peergroup dan perawat hemodialysa secara khusus dalam program asuhan keperawatan untuk dapat mempertahankan dan meningkatkan HRQoL khususnya pada aspek psikologis. Selanjutnya, melihat trend dengan follow-up yang lebih lama terkait perubahan seluruh dimensi $H R Q o L$ dengan jumlah sampel yang homogen dan lebih besar direkomendasikan untuk dapat diteliti pada penelitian selanjutnya.

\section{UCAPAN TERIMAKASIH}

Ucapan terimakasih kami sampaikan kepada LPPM Universitas 'Aisyiyah Yogyakarta atas segala supportnya dan kepada seluruh respondents yang telah berpartisipasi dalam penelitian ini.

\section{REFERENSI}

Abd ElHafeez, S., Sallam, S. A., Gad, Z. M., Zoccali, C., Torino, C., Tripepi, G., ... Awad, N. M. (2012). Cultural adaptation and validation of the "Kidney Disease and Quality of Life--Short Form (KDQOL-SF ${ }^{\mathrm{TM}}$ ) version 1.3" questionnaire in Egypt. BMC nephrology, 13, 170-170. doi:10.1186/1471-2369-13-170

Alexopoulou, M., Giannakopoulou, N., Komna, E., Alikari, V., Toulia, G., \& Polikandrioti, M. (2016). THE EFFECT OF PERCEIVED SOCIAL SUPPORT ON HEMODIALYSIS PATIENTS' QUALITY OF LIFE. Materia socio-medica, 28(5), 338-342. doi:10.5455/msm.2016.28.338-342
Anees, M., Hameed, F., Mumtaz, A., Ibrahim, M., \& Saeed Khan, M. N. (2011). Dialysis-related factors affecting quality of life in patients on hemodialysis. Iran J Kidney Dis, 5(1), 9-14.

Cha, J., \& Han, D. (2020). Health-Related Quality of Life Based on Comorbidities Among Patients with End-Stage Renal Disease. Osong public health and research perspectives, 11(4), 194200. doi:10.24171/j.phrp.2020.11.4.08

Dąbrowska-Bender, M., Dykowska, G., Żuk, W., Milewska, M., \& Staniszewska, A. (2018). The impact on quality of life of dialysis patients with renal insufficiency. Patient Prefer Adherence, 12, 577-583. doi:10.2147/ppa.s156356

Elhadad, A. A., Ragab, A. Z. E. A., \& Atia, S. A. A. (2020). Psychiatric comorbidity and quality of life in patients undergoing hemodialysis. Middle East Current Psychiatry, 27(1), 9. doi:10.1186/s43045-020-0018-3

Feroze, U., Noori, N., Kovesdy, C. P., Molnar, M. Z., Martin, D. J., Reina-Patton, A., . . KalantarZadeh, K. (2011). Quality-of-life and mortality in hemodialysis patients: roles of race and nutritional status. Clinical journal of the American Society of Nephrology : CJASN, 6(5), 1100-1111. doi:10.2215/CJN.07690910

Halpern-Manners, A., Schnabel, L., Hernandez, E. M., Silberg, J. L., \& Eaves, L. J. (2016). The Relationship between Education and Mental Health: New Evidence from a Discordant Twin Study. Social Forces, 95(1), 107-131. doi:10.1093/sf/sow035

Hill, N. R., Fatoba, S. T., Oke, J. L., Hirst, J. A., O'Callaghan, C. A., Lasserson, D. S., \& Hobbs, F. D. (2016). Global Prevalence of Chronic Kidney Disease - A Systematic Review and Meta-Analysis. PLoS One, 11(7), e0158765. doi:10.1371/journal.pone.0158765

Joshi, U., Subedi, R., Poudel, P., Ghimire, P. R., Panta, S., \& Sigdel, M. R. (2017). Assessment of quality of life in patients undergoing hemodialysis using WHOQOL-BREF questionnaire: a multicenter study. International journal of nephrology and renovascular disease, 10, 195-203. doi:10.2147/IJNRD.S136522

Joshi, V. D. (2014). Quality of life in end stage renal disease patients. World journal of nephrology, 3(4), 308-316. doi:10.5527/wjn.v3.i4.308

Mulia, D. S., Mulyani, E., Pratomo, G. S., \& Chusna, N. (2018). Kualitas hidup pasien gagal ginjal kronis yang menjalani hemodialisis di rsud dr. Doris sylvanus Palangka raya. Jurnal Keperawatan Silampari (JKS), Volume 1(2). 
Novitasari, L., Perwitasari, D. A., \& Khoirunisa, S. (2016). Validity of short form 36 (SF-36) Indonesian version on rheumatoid arthritis patients. 2016, 7. doi:10.20885/JKKI.Vol7.Iss3.art2

Park, J. I., Baek, H., \& Jung, H. H. (2016). Prevalence of Chronic Kidney Disease in Korea: the Korean National Health and Nutritional Examination Survey 2011-2013. Journal of Korean medical science, 31(6), 915-923. doi:10.3346/jkms.2016.31.6.915

Perl, J., Karaboyas, A., Morgenstern, H., Sen, A., Rayner, H. C., Vanholder, R. C., . . . Tentori, F. (2017). Association between changes in quality of life and mortality in hemodialysis patients: results from the DOPPS. Nephrology Dialysis Transplantation, 32(3), 521-527. doi:10.1093/ndt/gfw233

Rahayu, F., Ramlis, R., \& Fernando, T. (2018). Hubungan frekuensi hemodialisis dengan tingkat stres pada pasien gagal ginjal kronik yang menjalani hemodialisis. Jurnal Keperawatan Silampari (JKS), 1.

Ramatillah, D. L., Syed Sulaiman, S. A., Khan, A. H., \& Meng, O. L. (2017). Quality of Life among Patients Undergoing Hemodialysis in Penang, Malaysia. Journal of pharmacy \& bioallied sciences, 9(4), 229-238. doi:10.4103/jpbs.JPBS_191_17

Ricardo, A. C., Hacker, E., Lora, C. M., Ackerson, L., DeSalvo, K. B., Go, A., . . Lash, J. P. (2013). Validation of the Kidney Disease Quality of Life Short Form 36 (KDQOL-36) US Spanish and English versions in a cohort of Hispanics with chronic kidney disease. Ethn Dis, 23(2), 202-209.

Riskesdas. (2018). Badan Penelitian dan Pengembangan Kesehatan Kementerian Kesehatan Republik Indonesia,.

Romero, M., Vivas-Consuelo, D., \& Alvis-Guzman, N. (2013). Is Health Related Quality of Life (HRQoL) a valid indicator for health systems evaluation? SpringerPlus, 2(1), 664. doi:10.1186/2193-1801-2-664

Salim, S., Yamin, M., Alwi, I., \& Setiati, S. (2017). Validity and Reliability of the Indonesian Version of SF-36 Quality of Life
Questionnaire on Patients with Permanent Pacemakers. Acta Med Indones, 49(1), 10-16.

Suwanti, Taufikurrahman, Imron, M. R., \& Wakhid, A. (2017). Gambaran Kualitas Hidup Pasien Gagal Ginjal Kronis Yangmenjalani Terapi Hemodialisa. Jurnal Keperawatan, 5(2), 107114.

Theodoritsi, A., Aravantinou, M. E., Gravani, V., Bourtsi, E., Vasilopoulou, C., Theofilou, P., \& Polikandrioti, M. (2016). Factors Associated with the Social Support of Hemodialysis Patients. Iran J Public Health, 45(10), 12611269.

Untas, A., Thumma, J., Rascle, N., Rayner, H., Mapes, D., Lopes, A. A., . . . Combe, C. (2011). The associations of social support and other psychosocial factors with mortality and quality of life in the dialysis outcomes and practice patterns study. Clinical journal of the American Society of Nephrology : CJASN, 6(1), 142-152. doi:10.2215/CJN.02340310

Varghese, S. A. (2018). Social Support: An Important Factor for Treatment Adherence and Healthrelated Quality of Life of Patients with Endstage Renal Disease. Journal of Social Service Research, 44(1), 1-18. doi:10.1080/01488376.2017.1374315

Vassalotti, J. A., Centor, R., Turner, B. J., Greer, R. C., Choi, M., \& Sequist, T. D. (2016). Practical Approach to Detection and Management of Chronic Kidney Disease for the Primary Care Clinician. Am J Med, 129(2), 153-162.e157. doi:10.1016/j.amjmed.2015.08.025

Webster, A. C., Nagler, E. V., Morton, R. L., \& Masson, P. (2017). Chronic Kidney Disease. Lancet, 389(10075), 1238-1252. doi:10.1016/s0140-6736(16)32064-5

Winata, L. C. W. P., Putranto, W., \& Fanani, M. (2017). Association between Hemodialysis Adequacy, Family Support, and Quality of Life in Chronic Renal Failure Patients. Indonesian Journal of Medicine.

Zega, B. S., Subronto, Y. W., \& Padmawati, R. S. (2018). Edukasi Kesehatan Bagi Pasien Penderita Gagal Ginjal Kronis yang Menjalani Terapi Hemodialisis di RSUP Dr. Sardjito Yogyakarta. 